\title{
Investigating Insensitivity to Prior Probabilities in Merger and Acquisition (M\&A) Decision Making
}

\author{
James A. McGaughan \\ State University of New York at Albany \\ jmcgaughan@albany.edu
}

\author{
InduShobha Chengalur-Smith \\ State University of New York at Albany \\ shobha@albany.edu
}

\begin{abstract}
In this paper we investigate the high failure rates of Mergers and Acquisitions (M\&As) over the last several decades, despite greater access to data, sophisticated business intelligence (BI) and data analytics (DA) tools, and work by industry professionals and academics to improve outcomes. We explore the possibility that the representativeness heuristic could play a role, and specifically, if prior probabilities are being ignored or discounted in M\&A evaluations. We confirm our hypothesis using a regression discontinuity in time (RDiT) model and a two-way fixed effects model. By highlighting the negative consequences of this heuristic on management decisions, we promote the use of datadriven decision making and the role of analytics in formulating business strategy.
\end{abstract}

\section{Introduction}

As we entered the $21^{\text {st }}$ century, there was a belief that as data exploded and computing power became more powerful, Business Intelligence (BI) and Data Analytics (DA) could dramatically increase the success rate of operational and strategic decision making (SDM) [1]. In the business sphere, SDM can be defined as "a strategic decision which is important, in terms of the actions taken, the resources committed, or the precedents set" [2]. These are less frequent than the day to day operational decisions and are more fundamental to the overall long-term prospects of the organization.

Businesses pounced on this opportunity. In 2011, a survey conducted by Bloomberg revealed that $97 \%$ of all businesses with revenues exceeding $\$ 100$ million were found to be using some form of analytics [3]. Despite the highly anticipated returns from these initiatives, results have been disappointing, particularly in SDM. In 2016, after years of investment and orientation towards decision making supported by highly sophisticated BI tools, PwC found that two-thirds $(61 \%)$ of business leaders surveyed acknowledged their companies were not consistently making decisions guided by data and didn't consider their own organizations to be highly data-driven [4]. A year later, a survey of 2,200 business executives conducted by
McKinsey revealed that $72 \%$ thought bad strategic decisions were either as frequent as good ones or were the prevailing type within their organization. So it is clear that even with investment in technology and sincere effort, there remains a very large gap between optimal SDM and the current state of affairs.

One great example of SDM is M\&As. M\&As have been a very popular proposition for firms to achieve strategic objectives and have remained that way for decades, this is demonstrated in Figure 1. With such M\&A fervor, one could easily draw the conclusion that M\&As are a consistent source of success for organizations. This is not the case. In November of 1999, a landmark study on M\&A failure rates was published by KPMG. They looked at 700 M\&As across 107 companies, mainly large, cross-border deals that took place between 1996-1998. What they found was that although many business executives subjectively classified their M\&As as "successful", when evaluated by an objective measure such as shareholder value, this was not the case. In fact, $83 \%$ of all M\&As reviewed had either no impact or a negative impact on the organization [5]. A subsequent review of all the existing literature on $\mathrm{M} \& \mathrm{As}$ found that failure rates were between 70\%-90\% [6]. More recently, the global consulting firm LEK published findings that showed $60 \%$ of all M\&As destroy shareholder value [7].

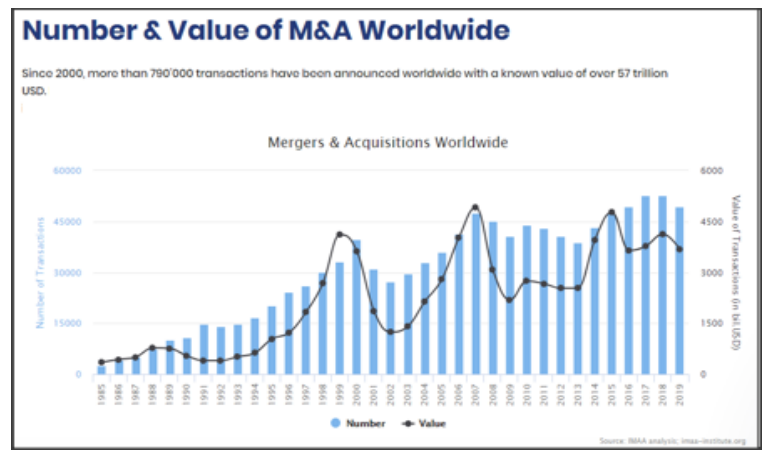

Figure 1. The Institute for Mergers, Acquisitions and Alliances (IMAA, 2020)

These persistent failure rates have compelled researchers to propose various critical success factors 
over the years, such as project planning, cultural match, strategic alignment, integration of human capital and more [5][6][7][8][9][10][11][12][13][14]. A summary of our literature review on traditional factors contributing to failure rates can be seen in Table 1. Yet, even after taking these factors into account, high failure rates persist.

There has been quite a bit of work done in Behavioral Economics and Experimental Psychology that shows humans are afflicted by the use of heuristics, biases, and intuition when tackling complex prediction problems [15]. Heuristics, biases, and intuition can be considered a benefit when making most minor decisions, like whether to cross the street or not. There are even some rare cases where the use of day to day heuristics by experts has been considered central to business strategy [16]. However, when larger, more complex decisions are contemplated without significant time pressure, they are generally considered flaws, and inhibit optimal outcomes [15].

Table 1. Traditional Factors Literature Review Summary

\begin{tabular}{|l|l|}
\hline \multicolumn{1}{|c|}{ Factors } & \multicolumn{1}{|c|}{ Source } \\
\hline Cultural Match & $\begin{array}{l}\text { (KPMG., 1999) } \\
\text { (Christensen et al, 2011) } \\
\text { (Marks, \& Marvis, 2011) } \\
\text { (Bauer \& Matzler, 2014) } \\
\text { (Bauer, Matzler, \& Wolf, 2016) }\end{array}$ \\
\hline Right Goal, Wrong Candidate/Strategic Alignment & $\begin{array}{l}\text { (Christensen et al., 2011) } \\
\text { (Bauer \& Matzler, 2014) } \\
\text { (Baker \& Niederman, 2014) }\end{array}$ \\
\hline Integration of Human Capital & $\begin{array}{l}\text { Christensen et al., 2011) } \\
\text { (Bauer \& Matzler, 2014) } \\
\text { (Bauer, Matzler, \& Wolf, 2016) }\end{array}$ \\
\hline Adequate Due Diligence and Rigorous Process & $\begin{array}{l}\text { (KPMG, 1999) } \\
\text { (Bruner, 2005) } \\
\text { (Lews,\& McKone, 2016) }\end{array}$ \\
\hline Making Sure the New Business can be \\
Managed/Management Team & $\begin{array}{l}\text { KPMG, 1999) } \\
\text { (Marks, \& Marvis, 2011) } \\
\text { (Lewis,\& McKone, 2016) }\end{array}$ \\
\hline Recent Experiences/Overconfidence/CEO Hubris & $\begin{array}{l}\text { (Bruner, 2005) } \\
\text { (Haleblian, Kim, \& Rajagopalan, 2006) } \\
\text { (Marks, \& Marvis, 2011) }\end{array}$ \\
\hline Project Planning, Meeting the Challenge of Complexity & $\begin{array}{l}\text { KPMG, 1999) } \\
\text { (Bruner, 2005) }\end{array}$ \\
\hline Finding Synergies & $\begin{array}{l}\text { (KPMG, 1999) } \\
\text { (Garzella \& Fiorentino, 2014) }\end{array}$ \\
\hline Flexibility for Challenges/Adapt to Change & $\begin{array}{l}\text { (Bruner,, 2005) } \\
\text { (Marks, \& Marvis, 2011) }\end{array}$ \\
\hline Valuation of Assets & (Christensen et al., 2011) \\
\hline Poor Communication & (KPMG, 1999) \\
\hline Departing from Business as Usual & (Bruner, 2005) \\
\hline
\end{tabular}

This research goes beyond traditional factors to consider if cognitive bias, specifically the representativeness heuristic, is playing a role in persistent failure rates. The representativeness heuristic is a shortcut that the human mind often takes when assessing if one thing belongs with another. This shortcut means prior probabilities are often not weighted appropriately in the decision-making process. This likely has serious consequences for SDM in business [15][17][18]. With this lens, we use econometric modeling to examine the effects of published high failure rates, which should have served as a strong prior probability for decision making. Our research question is as follows:
RQ: Does insensitivity to prior probabilities negatively impact M\&A outcomes?

\section{Literature Review}

A domain of major cognitive biases, and the focus of this paper is the representativeness heuristic [19]. This heuristic says that individuals will assess a subjective probability of an event based on two things: (1) the degree to which the item is similar in essential characteristics to its parent population and (2) the degree to which the item reflects the salient features of the process by which it is generated [19]. Several experiments have been conducted to detect this cognitive bias. Kahneman (2011) talks about an experiment they did where the following information was provided: "Steve is very shy and withdrawn, invariably helpful but with little interest in people or in the world of reality. A meek and tidy soul, he has a need for order and structure, and a passion for detail." The question is then asked of respondents: "Is Steve more likely to be a librarian or a farmer." In this example the qualitative information provided for "Steve" creates the representation of a librarian. A person who hides in books, works in a place of silence, and is not required to use brute force. The description convinces the mind that Steve must be a librarian; however, that qualitative information that creates the representation in the mind is low quality as it relates to making accurate predictions. For example, there are 20 times more farmers in the US than there are librarians [15]. These statistical realities are far more important for making accurate predictions, given that most professions have a diverse group of practitioners. There is some evidence that hiring practices are adversely impacted by biases such as the representativeness heuristic [15].

A major form of bias that falls within the representativeness heuristic, with plenty of empirical support, is "insensitivity to prior probabilities" [20]. For classification problems it can also be called the "base rate fallacy" [21]. The distinction is simply the difference between prediction vs. classification, but the bias mechanism is the same. This bias means people underweight or ignore past outcomes or base rates in making a prediction or classification decision [15][22]. One experiment was conducted where subjects were shown a personality description, randomly selected from a group of engineers and lawyers, and asked to assess whether they were an engineer or a lawyer. In one condition there were no base rates were provided, in another the subjects were provided a base rate of 70 engineers and 30 lawyers, and in the last condition the subjects were provided a base rate of 30 engineers and 70 lawyers. In a sharp departure from what a rational Bayes model would dictate, all produced similar results, 
the base rates had no impact on the decision-making process [17]. Additional experiments have shown the level of insensitivity to prior probabilities or base rates can be altered by extreme rates, which may be recognized intuitively as relevant [23][24]. For example, if a prior probability is 60/40, it is likely to be discounted or discarded in favor of other, more easily processed qualitative information. However, if the prior probability is $95 / 5$, there is some evidence that it may be recognized and processed as relevant [25][24]. The presence and behavior of this bias has many implications for SDM, particularly in decisions like M\&As, where there are complex evaluation processes in place, but little to no focus on prior probabilities. This would lead to persistent high failure rates until the problem is acknowledged, and the process is debiased.

With significant evidence that SDM is corrupted by cognitive biases, we aim to provide evidence of their presence in a particular strategic decision, M\&As. Specifically, we look to see if there is behavior change at the individual or group level when exposed to high failure rates, which should have an impact on future decision making and levels of confidence. We will do this with a quantitative approach using two different econometric methods and applying them to firm level M\&A data.

\section{Data \& Methods}

Our hypothesis regarding our research question (RQ) stated previously is as follows:

\section{Hypothesis: As new information is introduced showing higher failure rates in M\&As than previously known, decision makers' attitudes toward M\&As will remain stable, demonstrating insensitivity to prior probabilities.}

To test our hypothesis, we use a quantitative approach. Given the availability of rich, publicly available data, we begin with a Sharp Regression Discontinuity in Time (RDiT) model [26] on publicly available data from the Institute for Mergers, Acquisitions and Alliances (IMAA) as a preliminary test. Given the preliminary evidence we found regarding the apparent presence of insensitivity to prior probabilities in M\&A decision making, we then acquired a much larger data set from Bloomberg and analyzed it using a two-way fixed effects model. Both of these data sets were supplemented with control variables from various sources based on domain literature.

\subsection{Regression Discontinuity in Time (RDiT)}

The data for this initial analysis came from three sources. The M\&A data came from the Institute of Mergers, Acquisitions, and Alliances (IMAA). Since fluctuations by industry are more important to businesses and economic phenomenon than fluctuations by country, the data was aggregated across the 14 top industries by year, from 1985 - 2018. Additional graphs for $M \& A$ trends in both value and number can be seen in Figures 2 and 3.

There are many factors that can impact M\&A activity. Interest rates, company balance sheets, tax cuts, technology leading to enhanced efficiency, and more [27]. Many of these factors are related to the strength of economic growth. To control for macroeconomic conditions, economic data for covariates was pulled from two additional sources. The first economic covariate, Gross World Product (GWP), is the accumulated value of all finished goods and services produced across all countries, measured annually in billions of USD [29]. This controls for fluctuations in the world economy and was retrieved from the Statista (2018) website. The trend of GWP over time from 1990 - 2018 can be seen in Figure 4.

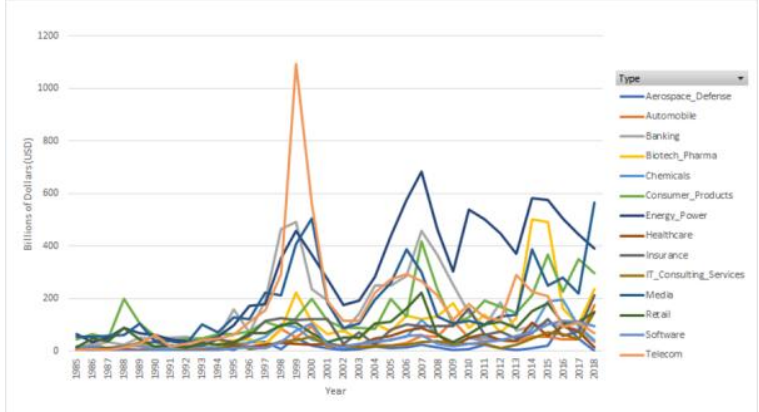

Figure 2. M\&As in Billions (USD) by Industry (1985 2018)

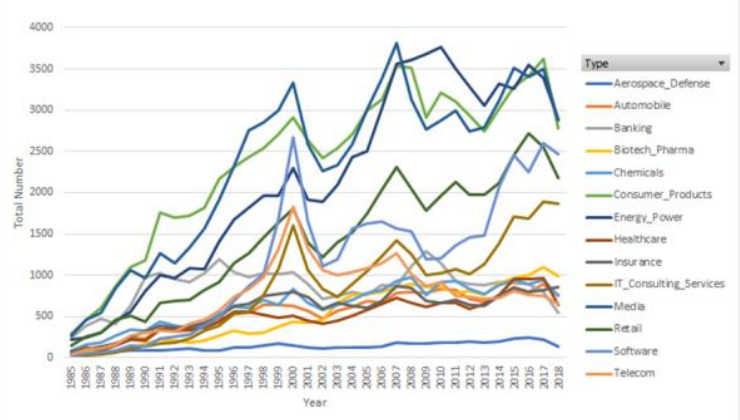

Figure 3. M\&As (Total Number) by Industry (1985 2018)

The second economic covariate, taken from the International Monetary Fund's (IMF) website, was the years that have been flagged as a "global recession" by 
the following IMF definition: "years where the global GDP rates of growth were at 3\% or less" [30]. There were 9 years of global recession 1990-1993, 1998, 2001-2002, and 2008-2009. This covariate specifically controls for recession level downturns where we might see a sharp drop in M\&A activity. We limited economic controls to these two given the availability of highquality data at the global level.

The method used for this analysis is a Sharp Regression Discontinuity in Time (RDiT) model [26]. The analysis was conducted with Stata software. RDiT is a fairly new method that facilitates the examination of treatment effects across an intervention or event that occurs in time. It is appropriate when randomization is infeasible and uses a quasi-experimental pre- and posttest approach to establish the causal effects of interventions. By comparing observations lying closely on either side of an assigned cut-off, it is possible to estimate the average effect of the intervention. RDiT is not constrained by unobservables that can affect the outcome variable, as long as they do not change discontinuously at the threshold [26]. Given its nonparametric nature, it also allows for the possibility of uncovering heterogenous treatment effects by using a local linear fit within each band, called bandwidth [31][32]. The ability to set small bands allows for high precision estimates as it will refit the regression each time as you go away from the cutoff.

RDiT has been used to study the impact of regulations on the marketplace, public transit strikes on traffic congestion, promotions on economic activity, and more [32][33][34]. Thus, RDiT models are well suited to identify whether the targeted activity, in this case M\&As over time, responds to new information. In our case, the intervention is the 1999 KPMG study and the cut-off was therefore assigned at 1999. The model was run separately for two dependent variables: value of M\&As (in billions of USD) and number of M\&As. An assumption of rationality (i.e. sensitivity to prior probabilities) would create the expectation of a treatment effect, or a change in M\&A behavior, after the cutoff of 1999, when decision makers have been exposed to the published high failure rates [17].

We controlled for fluctuations in industry, GWP, and recessions. Additionally, because the economic control variables were only available from 1990 on, the years of 1985 - 1989 were dropped, so that we would have complete information for each observation. Given the collinearity between the two economic covariates, GWP and the recession indicator, we ran a factor analysis for the discrete (GWP) and dichotomous (recessions) variables that produced a single economic covariate. The results of the factor analysis are shown in Table 2. We also dropped the telecom industry variable due to multicollinearity. This brought our total number of observations down from $\mathrm{N}=476$ to $\mathrm{N}=405$. Our two RDiT models for value and count and a discussion of the results are provided in Section 4.1.

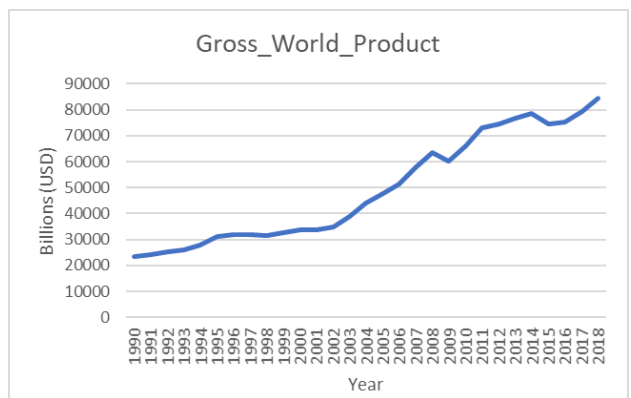

Figure 4. Gross World Product in Billions (GWP) (1990 - 2018)

Table 2. Factor Analysis

\begin{tabular}{|l|l|l|l|l|}
\hline Factor & Eigenvalue & Difference & Proportion & Cumulative \\
\hline Factor 1 & 0.936 & 1.178 & 1.349 & 1.349 \\
\hline Factor2 & -0.242 & - & -0.349 & 1 \\
\hline $\begin{array}{l}\text { LR Test: Independent vs. Saturated Chi-sq(1) }=171.84, \text { Prob > chi-sq } \\
=0.00\end{array}$ \\
\hline
\end{tabular}

\subsection{Two-way Fixed Effects}

Given the preliminary evidence for our hypothesis, we sought to refine and validate our results. M\&A activity tends to be highly concentrated in places like Europe and North America, and to a lesser degree, Asia. After that there is a large drop off [28]. Additionally, we tend to see M\&A activity positively correlate with the strength of economies around the world [35][36]. Hence, we significantly expanded our sample and also controlled for economic strength and asymmetrical concentration of M\&A deal-making. So, in addition to the treatment variable of interest (KPMG), and companies that use KPMG as an auditor (KPMG as auditor), we also added Country GDP by year (GDP), region, industry, type of market (World (Developed) vs. Emerging vs. Frontier), and deal status (completed vs terminated).

We also wished to ensure that our results were not an artifact of the particular econometric method we used. Thus, we turned to a different type of analysis for this much larger data set. This analysis was also conducted with Stata software. Given the granular nature of the Bloomberg data set, and the potential for time and country (unit) variation, a two-way fixed effects model is a great econometric tool to isolate treatment effects given different baselines [37]. To get a robust set of panels for our two-way fixed effects analysis we needed to go through a lengthy process. This lengthy, end-to-end process can be seen in Figure 5. 
Industries were consolidated from 23 to 10 based on outlier groups that had fewer than 20 transactions and could be reasonably associated with other industries. We needed to create panel data that would be suitable for our fixed effects models. There were many transactions per day and some units had multiple transactions in a single day. This motivated us to create monthly panels. The data was collapsed by month and country and dichotomous variables that existed for individual transactions were converted to rolled up numerical variables by specific month. This was done for industry, region, type of market, deal status, and KPMG auditor. Deal value was also summed up by month and country so that one value would exist for each unit in each time period. This gave us an $\mathrm{N}=3,797$.

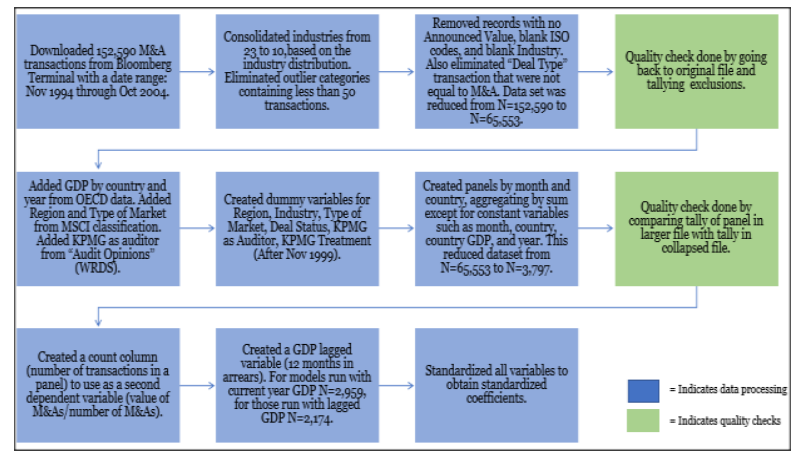

Figure 5. Data processing for 152,590 M\&A records from Bloomberg

The data we used for this study came from a variety of sources. The main source of data came from Bloomberg Terminal (2020) and included all M\&A transactions, dates, countries, industry data, deal status and deal value [40]. In addition to the core data set we added GDP by year and country from the Organization for Economic Co-operation and Development (OECD) (2020) [38]. We were able to organize the countries by region according to the MSCI classification Index, an industry standard[39]. We also used the type of market from MSCI (2020) to add another control variable. Because we were specifically interested in the treatment effect of whether decision makers were considering the KPMG report in 1999 and the impact it may have had, we added two variables related to this. One was a dummy variable coded 0 prior to December of 1999 and 1 thereafter. Since the report was published in November of 1999, this control variable tracked access to the report. We also wanted to know if there was a mitigating effect for clients who used KPMG as an auditor, due to the fact that there may have been more awareness regarding the report for KPMG clients. This information was obtained from "Audit Opinions" from the Wharton Research Data Services (WRDS) website
[46]. Our models for value and count and a discussion of the results are provided in Section 4.2.

\section{Results}

\subsection{Regression Discontinuity in Time (RDiT)}

The analysis comprised of two models. Model 1 used the value of M\&As per year (in billions of USD) as its dependent variable and Model 2 used the total of M\&As per year as its dependent variable. The control variables in both models were the industry dichotomous variables and Factor1, which was a synthetic variable made up of GWP and a recession indicator. Both models can be seen below in Table 3 .

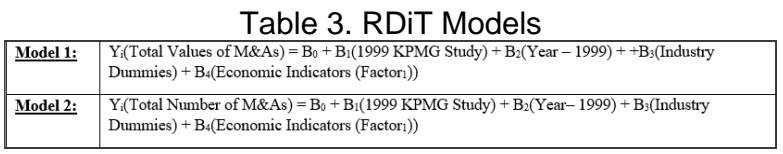

We first present the results for the value of M\&As (Model 1). The graphical representation (Figure 6) and model (Table 4) show a fairly small (79.98 billion), but statistically significant $(\mathrm{z}=2.58)$ negative discontinuity (reduction in value of M\&As) after 1999. The value of the coefficient represents the distance from the start of the regression curve to the right of the cutoff, to the end of the regression curve to the left of the cutoff. To check the robustness of our results, we also conducted a sensitivity analysis by removing the covariates (Figure 7; Table 6). The discontinuity remained negative but lost some significance $(\mathrm{z}=1.85)$ and shrank by about $34 \%$ to 52.6 billion.

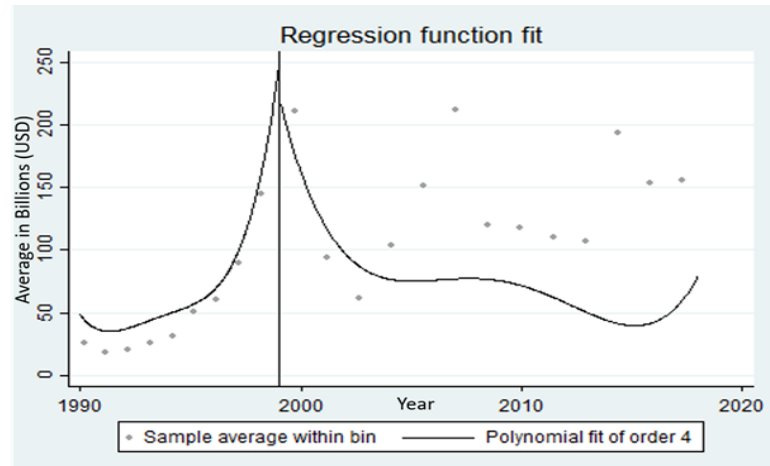

Figure 6. RDiT for M\&As in Billions (USD)

The second analysis used the number of M\&As per year as the dependent variable. The graphical representation (Figure 8) and model (Table 6) show a large (- 492.04), but a highly statistically significant positive discontinuity after 1999 . This represents a sharp increase in the number of M\&As from 1999 to 2000. We 
also conducted a sensitivity analysis by removing the covariates (Figure 9; Table 7). This created significant issues with the findings. The prior bandwidth of 2.24 was no longer accepted by the software package, so it was increased to 2.75 . With the new bandwidth, the plot looked fairly similar, but the RDiT model produced a coefficient of 78.109 and all statistical significance was lost $(\mathrm{z}=1.1)$.

Table 4. RDiT for M\&As in Billions (USD)
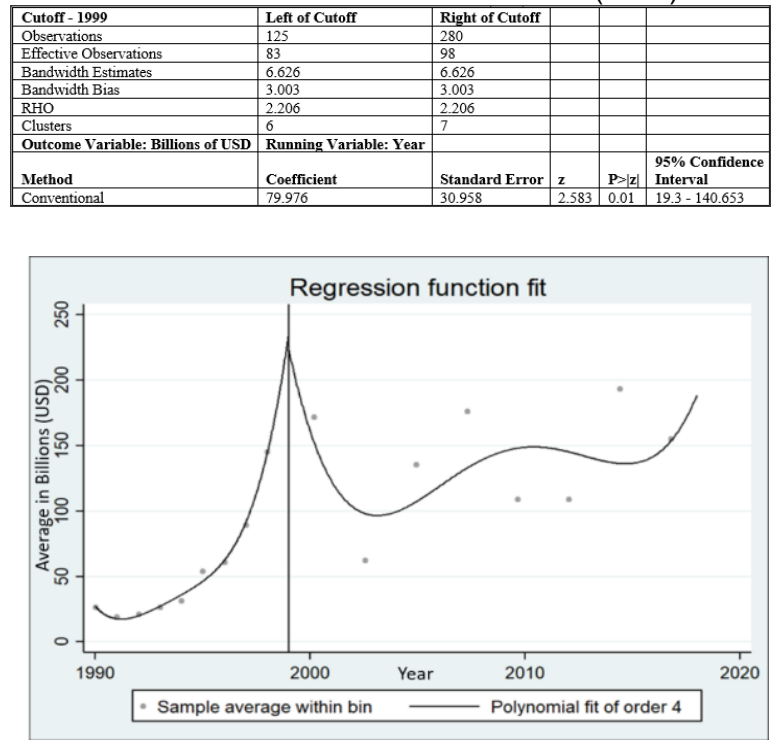

Figure 7: Sensitivity Analysis - RDiT for M\&As in Billions (USD)

Table 5. Sensitivity Analysis - RDiT for M\&As in Billions (USD)

\begin{tabular}{|l|l|l|l|l|l|}
\hline Cutoff - 1999 & Left of Cutoff & $\begin{array}{l}\text { Right of } \\
\text { Cutoff }\end{array}$ & & & \\
\hline Observations & 126 & 280 & & & \\
\hline Effective Observations & 84 & 98 & & & \\
\hline Bandwidth Estimates & 6.62 & 6.62 & & & \\
\hline Bandwidth Bias & 6.62 & 6.62 & & & \\
\hline RHO & 1 & 1 & & & \\
\hline Clusters & 6 & 7 & & & \\
\hline $\begin{array}{l}\text { Outcome Variable: Billions of } \\
\text { USD }\end{array}$ & $\begin{array}{l}\text { Running Variable: } \\
\text { Year }\end{array}$ & & & & \\
\hline Method & Coefficient & $\begin{array}{l}\text { Standard } \\
\text { Error }\end{array}$ & $\mathbf{z}$ & $\mathbf{P}>|\mathbf{z}|$ & $\begin{array}{l}95 \% \text { Confidence } \\
\text { Interval }\end{array}$ \\
\hline Conventional & 52.625 & 28.448 & 1.85 & 0.064 & $-3.132-108.383$ \\
\hline
\end{tabular}

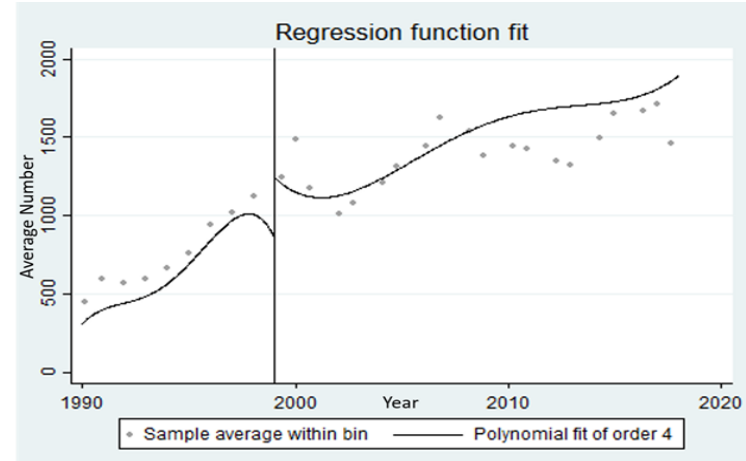

Figure 8: RDiT for M\&As in Numbers
Table 6. RDiT for M\&As in Numbers

\begin{tabular}{|c|c|c|c|c|c|}
\hline Cutoff - 1999 & Left of Cutoff & \begin{tabular}{|l|} 
Right of \\
Cutoff
\end{tabular} & & & \\
\hline Observations & 125 & 280 & & & \\
\hline Effective Observations & 28 & 42 & & & \\
\hline Bandwidth Estimates & 2.243 & 2.243 & & & \\
\hline Bandwidth Bias & 3.807 & 3.807 & & & \\
\hline $\mathrm{RHO}$ & 0.589 & 0.589 & & & \\
\hline Clusters & 3 & 4 & & & \\
\hline $\begin{array}{l}\text { Outcome Variable: Billions } \\
\text { of USD }\end{array}$ & \begin{tabular}{|l|} 
Running \\
Variable: Year
\end{tabular} & & & & \\
\hline Method & Coefficient & \begin{tabular}{|l|} 
Standard \\
Error
\end{tabular} & $\mathrm{z}$ & $\mathbf{P}>\mathbf{z} \mid$ & $\begin{array}{l}\text { 95\% Confidence } \\
\text { Interval }\end{array}$ \\
\hline Conventional & -492.04 & $3.40 \mathrm{E}-07$ & $1.50 \mathrm{E}+09$ & 0 & $\begin{array}{l}-492.043 \cdots \\
492.043\end{array}$ \\
\hline
\end{tabular}

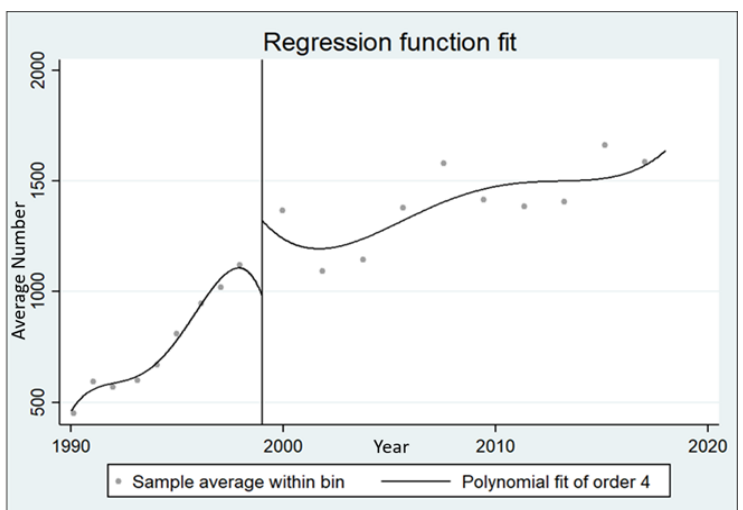

Figure 9: Sensitivity Analysis - RDiT for M\&As in Numbers

Table 7: Sensitivity Analysis - RDiT for M\&As in Numbers

\begin{tabular}{|l|l|l|l|l|l|}
\hline Cutoff- 1999 & Left of Cutoff & $\begin{array}{l}\text { Right of } \\
\text { Cutoff }\end{array}$ & & & \\
\hline Observations & 126 & 280 & & & \\
\hline Effective Observations & 28 & 42 & & & \\
\hline Bandwidth Estimates & 2.75 & 2.75 & & & \\
\hline Bandwidth Bias & 2.75 & 2.75 & & & \\
\hline RHO & 1 & 1 & & & \\
\hline Clusters & 2 & 3 & & & \\
\hline $\begin{array}{l}\text { Outcome Variable: Billions of } \\
\text { USD }\end{array}$ & $\begin{array}{l}\text { Running Variable: } \\
\text { Year }\end{array}$ & & & & \\
\hline Method & Coefficient & $\begin{array}{l}\text { Standard } \\
\text { Error }\end{array}$ & $\mathbf{z}$ & $\mathbf{P}>|\mathbf{x |}|$ & $\begin{array}{l}\mathbf{9 5 \%} \text { Confidence } \\
\text { Interval }\end{array}$ \\
\hline Conventional & 78.109 & 70.841 & 1.103 & 0.27 & $-60.7356-216.954$ \\
\hline
\end{tabular}

\subsection{Two-way Fixed Effects}

The monthly panels allow us to conduct analyses on both value (Mvalue ${ }_{i t}$ ) and count (Mcount ${ }_{i t}$ ) of M\&As by regressing these dependent variables on the variables of interest: (1) the availability of the KPMG report $\left(\mathrm{KPMG}_{\mathrm{it}}\right)$, and (2) the number of times KPMG served as auditor (KPMG as Auditor ${ }_{i t}$ ), and control variables such as the yearly GDP of that country in the current year $\left(\mathrm{GDP}_{\mathrm{it}}\right)$, the yearly GDP of that country in the prior year $\left(\mathrm{GDP}_{\mathrm{it}-1}\right)$ (separate models), the region of that country $\left(\right.$ Region $\left._{i t}\right)$, the industry distribution of the deals in that country for that month (Industryit), the deal status distribution (completed or terminated) of the deals in that country for that month (Deal Status $\mathrm{s}_{\mathrm{it}}$ ), and the type of market distribution of the deals in that country for that month (Type of Market ${ }_{i t}$ ). Upon running the models, records were eliminated for various missing values which gave a final observation count of $\mathrm{N}=2,959$ for 
current year GDP and N=2,174 for prior year GDP. The 4 models for value and count, regressed on current and prior year GDP, can be seen in Table 8 .

Table 8: Two-way Fixed Effects Models

\begin{tabular}{|c|c|}
\hline Model 1: & 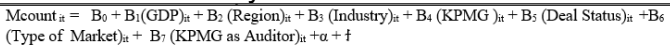 \\
\hline Model 2: & 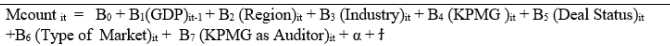 \\
\hline Model 3: & $\begin{array}{l}\text { Mvalue it }=B_{0}+B_{1}(G D P)_{)_{i t}}+B_{2}(\text { Region })_{i t}+B_{3}(\text { Industry })_{i t}+B_{4}(\text { KPMG })_{i t}+B_{5}(\text { Deal Status })_{i t} \\
+B_{6}(\text { Type of Market })_{i t}+B_{7}(\text { KPMG as Auditor })_{i t}+\alpha+t\end{array}$ \\
\hline Model 4: & $\begin{array}{l}\text { Mvalue it }=B_{0}+B_{1}(G D P)_{i t-1}+B_{2}(\text { Region })_{i t}+B_{3}(\text { Industry })_{i t}+B_{4}(K P M G)_{i t}+B_{5}(\text { Deal Status })_{i t} \\
+B_{6}(\text { Type of Market })_{i t}+B_{7}(\text { KPMG as Auditor })_{i t}+\alpha++\end{array}$ \\
\hline
\end{tabular}

Specifically, we used a two-way fixed effects model with a unit and time fixed effect to control for unobservables across countries (unit) and months (time). The goal of this model is to reduce endogeneity and tease out the true impact of new information to M\&A decision makers. We ran 8 distinct models which produced standardized coefficients. For value as a dependent variable (Mvalue ${ }_{i t}$ ) we ran two models with current year GDP (GDP $\left.{ }_{i t}\right)$ and two with prior year GDP $\left(\mathrm{GDP}_{\mathrm{it}-1}\right)$, varying standard errors between regular and robust, since GDP can be a predictor of M\&A activity, but the reaction time is unclear [41]. We followed this by doing the same for count (Mcount ${ }_{i t}$ ), where $\alpha=$ unit fixed effect and $f=$ time fixed effect. Note that $B_{1}=G D P$ for country and month (current and prior year used in distinct models), $\mathrm{B}_{2}=$ Region of the Particular Transaction, $\mathrm{B}_{3}=$ Industry of the Acquiring Firm, $\mathrm{B}_{4}=$ Whether or not deal makers had access to the KPMG Report (starting in December $1999=1,=0$ prior), $\mathrm{B}_{5}=$ Whether or not a deal was completed or terminated at some point in the process, $\mathrm{B}_{6}=$ Type of Market according to MSCI (World, Emerging, or Frontier), and $\mathrm{B}_{7}=$ Whether or not KPMG was the Acquiring company's auditor.

In model 1a, we evaluated count as the dependent variable with regular standard errors and current year GDP. For industry, Utilities served as our baseline, for markets, Frontier markets served as the baseline, and for region, Asia served as the baseline in our models. For all models, all coefficients positive or negative are relative to the baseline variables in that grouping. In model 1a we find that, controlling for factors previously mentioned, deal makers were not dissuaded by the KPMG report (variable of interest) stating that $83 \%$ of M\&As fail. The KPMG coefficient was a relatively small negative (-.0012) and was not statistically significant $(\mathrm{p}=.8)$. All industries were highly significant with Financials being the largest statistically significant positive influencer of number of deals (.1439***). Communications was also a large influencer of number of deals $(.1281 * * *)$. All regions were statistically significant, three at the .01 level with North America being the largest $(.0442 * * *)$. Current year GDP was statistically significant $(.0092 * * *)$ as was Deal Status
(Completed) (.3518***). Type of Market was not statistically significant. Interestingly, companies who had KPMG as an auditor were more likely to be impacted by the report (-.0004***), although this effect size is small.

In model $1 \mathrm{~b}$, we evaluated count as the dependent variable with robust standard errors and current year GDP. In model $1 \mathrm{~b}$ we also find that deal makers were not dissuaded by the KPMG report (variable of interest). The KPMG report remained statistically insignificant. All industries remained highly significant, but all regions lost their statistical significance in this model. Current year GDP remained statistically significant as did Deal Status (Completed). Type of Market was not statistically significant. Companies who had KPMG as an auditor remained statistically significant.

In model $2 \mathrm{a}$, we evaluated count as the dependent variable with regular standard errors but controlled for prior year GDP instead of current year. In model $2 \mathrm{a}$ we find that, controlling for factors previously mentioned, deal makers were not dissuaded by the KPMG report (variable of interest). The KPMG coefficient was a relatively small negative (-.0012) and was not statistically significant $(\mathrm{p}=.874)$. All industries were highly significant with Financials being the largest statistically significant positive influencer of number of deals $(.1400 * * *)$. Communications was also a large influencer of number of deals $(.1251 * * *)$. All regions were statistically significant, three at the .01 level with North America being the largest (.0457***). Current year GDP was statistically significant at the .1 level $(.0092 *)$ and Deal Status was highly significant (Completed) (.3625***). Type of Market was not statistically significant. Companies who had KPMG as an auditor were more likely to be impacted by the report $\left(-.0045^{* * *}\right)$.

In model $2 \mathrm{~b}$, we evaluated the same things as $2 \mathrm{a}$ except we used robust standard errors. In model $2 \mathrm{~b}$ we find that, controlling for factors previously mentioned, deal makers were not dissuaded by the KPMG report (variable of interest). The KPMG coefficient was relatively small and negative (-.0012) and was not statistically significant $(\mathrm{p}=.874)$. All industries were highly significant with Financials being the largest statistically significant positive influencer of number of deals $(.1400 * * *)$. Communications was also a large influencer of number of deals $(.1251 * * *)$. All regions were statistically significant, three at the .01 level with North America being the largest (.0457***). Current year GDP was statistically significant at the .1 level $(.0092 *)$ and Deal Status was highly significant (Completed) $(.3625 * * *)$. Type of Market was not statistically significant. Companies who had KPMG as an auditor were more likely to be impacted by the report 
(-.0045***). Model 1 and 2 standardized coefficients and p-values are below in Table 9 .

In model $3 \mathrm{a}$, we evaluated M\&A deal value as the dependent variable with regular standard errors and current year GDP. In model 3a we find that, controlling for factors previously mentioned, deal makers were not dissuaded by the KPMG report (variable of interest). The KPMG coefficient was negative (-.016) and was not statistically significant $(\mathrm{p}=.941)$. Four industries were statistically significant, two highly significant, Consumer Non-Cyclical (-.4307***) and Diversified ($.0863 * * *)$. For regions, only EMEA_CIS was significant at the .05 level (.1218**). Current year GDP was a statistically significant $(-.8783 * * *)$ negative influencer of deal values. Deal Status was highly positive influencer of deal values (Completed) (1.273***). World (Type of Market) was also positive $(.9448 * * *)$ and statistically significant. Companies who had KPMG as an auditor were more likely to be impacted by the report (-.1240***).

In model $3 b$, we evaluated M\&A deal value as the dependent variable with robust standard errors and current year GDP. In model $3 b$ we again find deal makers were not dissuaded by the KPMG report (variable of interest). The KPMG coefficient was not statistically significant $(\mathrm{p}=.788)$. Only Diversified remained highly significant for industry. Current year GDP remained statistically significant $(-.8783 * *)$ at the .05 level. Deal Status lost statistical significance. World (Type of Market) remained statistically significant. Companies who had KPMG as an auditor remained significant at the .05 level.

In model $4 \mathrm{a}$, we evaluated M\&A deal value as the dependent variable with regular standard errors but controlled for prior year GDP instead of current year. In model $4 \mathrm{a}$ we find that, controlling for factors previously mentioned, deal makers were not dissuaded by the KPMG report (variable of interest). The KPMG coefficient was negative (-.0224) and was not statistically significant $(\mathrm{p}=.946)$. Three industries were statistically significant, one highly significant, Consumer Non-Cyclical (-.4240***). For regions, only EMEA CIS was significant (.1989***). Prior year GDP was a statistically significant $(-1.3874 * * *)$ negative influencer of deal values. Deal Status was highly positive influencer of deal values (Completed) (1.094**). World (Type of Market) was also positive $(1.0411 * * *)$ and statistically significant. Companies who had KPMG as an auditor were more likely to be impacted by the report (-.1284***).

In model $4 \mathrm{~b}$, we evaluated the same things as $4 \mathrm{a}$ except we used robust standard errors. In model $4 \mathrm{~b}$ we again find deal makers were not dissuaded by the KPMG report (variable of interest). The KPMG coefficient was not statistically significant $(\mathrm{p}=.851)$.
Two industries were statistically significant, Consumer Non-Cyclical and Diversified. For regions, EMEA CIS remained highly significant. Prior year GDP also remained highly significant. Deal Status lost statistical significance. World (Type of Market) remained highly significant. Companies who had KPMG as an auditor remained highly significant at the .01 level. Model 3 and 4 standardized coefficients and p-values are in Table 10.

Table 9: Two-way Fixed Effects Model for Count

\begin{tabular}{|c|c|c|c|c|c|c|c|c|}
\hline Count & Model 1a & & Model $1 \mathrm{~b}$ & & Model 2a & & Model $2 \mathrm{~b}$ & \\
\hline & \begin{tabular}{|l|} 
lurrent \\
GDP/standard \\
Errors \\
\end{tabular} & & \begin{tabular}{|l} 
Current \\
GDP/Robust \\
Errors
\end{tabular} & & \begin{tabular}{|l} 
Prior Year \\
GDP/Standard \\
Errors
\end{tabular} & & $\begin{array}{l}\text { Prior Year } \\
\text { GDP/Robust } \\
\text { Errors }\end{array}$ & \\
\hline & Coefficient & P-value & Coefficient & P-value & Coefficient & P-value & Coefficient & P-value \\
\hline KPMG & -.0012 & .8000 & .0012 & .3580 & -0012 & .8740 & -.0012 & .6480 \\
\hline KPMG Auditor & $-.0004^{* z *}$ & .0000 & $-.0004^{* * *}$ & .0000 & $-.045^{* * z}$ & .0000 & $-.045^{* 2 z}$ & .0000 \\
\hline Country GDP in Current Year. & $.0092^{2 z z}$ & .0000 & $.0092^{* z z}$ & .0030 & N/A & $\mathrm{N} / \mathrm{A}$ & $\mathrm{N} / \mathrm{A}$ & $\mathrm{N} / \mathrm{A}$ \\
\hline Country GDP in Prior Year & $\mathrm{N} / \mathrm{A}$ & N/A & $\mathrm{N} / \mathrm{A}$ & N/A & $.0066^{*}$ & .0530 & $.0066^{* *}$ & .0490 \\
\hline EMEA_CIS & $.0076^{* s z}$ & .0000 & .0076 & .4820 & $.0078^{8 * z}$ & .0000 & .0078 & .5000 \\
\hline North America & $.0442^{2 s z}$ & .0000 & .0442 & .1350 & $.0457^{7 * z}$ & .0000 & .0457 & .1450 \\
\hline Pacific & $.0051^{1 z z}$ & .0000 & .0051 & .3800 & $.0055^{* * z}$ & .0000 & .0055 & .3720 \\
\hline Americas & $.0009^{* t}$ & .0440 & .0009 & .1090 & $.0013^{* x}$ & .0340 & $.0013^{* 2}$ & .0240 \\
\hline Asia & Baseline & Baseline & Baseline & Baseline & Baseline & Baseline & Baseline & Baseline \\
\hline Basic Materials & $.0400^{* s z}$ & .0000 & $.0400^{* z z}$ & .0000 & $.0380^{* x+}$ & .0000 & $.0380^{* \pm *}$ & .0000 \\
\hline Communications & $.1281^{1 * z}$ & .0000 & $.1281^{ \pm x z}$ & .0000 & $.1251^{1 * *}$ & .0000 & $.1251^{* \pm x}$ & .0000 \\
\hline Consumer Cydical & $.0655^{5 z z}$ & .0000 & $.0655^{* * z}$ & .0000 & $.0649^{g * z}$ & .0000 & $.0649^{* * *}$ & .0000 \\
\hline \begin{tabular}{|c|} 
Consumer Non-Cyclical \\
\end{tabular} & $.0974^{4 z z}$ & .0000 & $.0974^{* z+}$ & .0000 & $.0955^{* z+}$ & .0000 & $.0955^{* 2 *}$ & .0000 \\
\hline Diversified & $.0198^{8 * z}$ & .0000 & $.0198^{* * z}$ & .0000 & $.0196^{* * *}$ & .0000 & $.0196^{\mathrm{Hz}}$ & .0000 \\
\hline Energy & $.0422^{* s z}$ & .0000 & $0.0429^{ \pm x z}$ & .0000 & $.0422^{8 * z}$ & .0000 & $.0428^{=1 *}$ & .0000 \\
\hline Financial & $.1433^{p=s}$ & .0000 & $0.1439^{z=x}$ & .0000 & $.1400^{* z+}$ & .0000 & $.1400^{* 1 *}$ & .0000 \\
\hline Industrial & $.0777^{7 s z}$ & .0000 & $0.077^{* * z}$ & .0000 & $.0760^{3 * 3}$ & .0000 & $.0760^{* * z}$ & .0000 \\
\hline \begin{tabular}{|l} 
Technology \\
\end{tabular} & $.0669^{g z z}$ & .0000 & $0.0669^{* * z}$ & .0000 & $.0655^{5 * z}$ & .0000 & $.0655^{* 2 *}$ & .0000 \\
\hline \begin{tabular}{|l|l} 
\\
\end{tabular} & Baseline & Baseline & Baseline & Baseline & Baseline & Baseline & Baseline & Baseline \\
\hline Completed & $.3518^{ \pm z z}$ & .0000 & $.3518^{8 * z}$ & .0000 & $.3622^{5 s z}$ & .0000 & $.3625^{* a t}$ & .0000 \\
\hline Terminated & Baseline & Baseline & Baseline & Baseline & Baseline & Baseline & Baseline & Baseline \\
\hline World & -.0037 & .2010 & -.0037 & .5100 & -0028 & .4460 & -0028 & .6740 \\
\hline Emerging & -.0004 & .8830 & .0004 & .3460 & Omitted & omitted & Omilted & Omitted \\
\hline Frontier & Baseline & Baseline & Baseline & Baseline & \begin{tabular}{|l|} 
Baseline \\
\end{tabular} & Baseline & Baseline & Baseline \\
\hline
\end{tabular}

Table 10: Two-way Fixed Effects Model for Value

\begin{tabular}{|c|c|c|c|c|c|c|c|c|}
\hline Value & Model 3a & & Model $3 \mathrm{~b}$ & & Model 4a & & Model 4b & \\
\hline & \begin{tabular}{|l|} 
Current \\
GDP/standard \\
Errors \\
\end{tabular} & & $\begin{array}{l}\text { Current } \\
\text { GDP/Robust } \\
\text { Emors }\end{array}$ & & \begin{tabular}{|l|} 
Prior Year \\
GDP/Standard \\
Errors \\
\end{tabular} & & \begin{tabular}{|l} 
Prior Year \\
GDP/Robust \\
Errors \\
\end{tabular} & \\
\hline & Coefficient & p-value & Coefficient & \begin{tabular}{|l|} 
P-value \\
\end{tabular} & Coefficient & p-value & Coefficient & P-value \\
\hline KPMG & 0.0160 & 9410 & -0.0160 & .7880 & -0.024 & .9460 & -0.024 & .8510 \\
\hline KPMG Auditor & $-1240^{* z z}$ & .0020 & $-1.1240^{* z}$ & .0150 & $-1284^{ \pm * *}$ & .0050 & $-.1284^{* * z}$ & .0020 \\
\hline Country GDP in Current Year & $-8783^{* 2 *}$ & .0000 & $-8783^{* *}$ & .0430 & N/A & N/A & N/A & $\mathrm{N} / \mathrm{A}$ \\
\hline Country GDP in Prior Year & $\mathrm{N} / \mathrm{A}$ & N/A & $\mathrm{N} / \mathrm{A}$ & N/A & $-1.3874^{* \pm z}$ & .0000 & $-1.3874^{* * z}$ & .0010 \\
\hline EMEA_CIS & $.1218^{* *}$ & .0340 & $.1218^{* *}$ & .0380 & $.1989= \pm$ & .0050 & $.1989=2 *$ & .0000 \\
\hline North America & $-.3274^{*}$ & .0900 & $-3274^{* *}$ & .0320 & .2218 & .3500 & $-.2218^{*}$ & .0870 \\
\hline Pacific & -.0025 & .9420 & -.0025 & .9230 & .0312 & .4630 & .0312 & .1910 \\
\hline Americas & .0009 & .9620 & .0009 & .8900 & .0007 & .9800 & .0007 & 9080 \\
\hline Asia & Baseline & Baseline & Baseline & Baseline & Baseline & Baseline & Baseline & Baseline \\
\hline Basic Materials & -.0200 & .5980 & -.0200 & .7390 & -0.0129 & .7690 & -0.029 & 77390 \\
\hline Communications & 0116 & .8890 & .0116 & .9250 & -01966 & .8400 & -0.0196 & 8.8680 \\
\hline Consumer Cydical & $-1038^{* z}$ & .0490 & -1038 & .2800 & $-1190^{*}$ & .0550 & -1190 & .1380 \\
\hline Consumer Non-Cyclical & $-.4307^{* * *}$ & .0000 & $-4307^{* *}$ & .0110 & $-.4240^{ \pm \pm *}$ & .0000 & $-4240^{ \pm z *}$ & .0050 \\
\hline Diversified & $-0863^{* * *}$ & .0000 & $-.0863^{* \pm z}$ & .0000 & $-0.0586^{ \pm *}$ & .0180 & $-0586^{3 z z}$ & .0040 \\
\hline Energy & -0.053 & .4160 & -0.0353 & .3470 & -0099 & .8420 & -0.099 & .7090 \\
\hline Financial & $-2147^{* *}$ & .0440 & .2147 & .1090 & -1971 & .1160 & -1971 & .1280 \\
\hline Industrial & -0.0278 & .6660 & -0.0278 & .8750 & -.0760 & .6810 & -0.0760 & 8.840 \\
\hline Technology & -.0363 & .5210 & $\begin{array}{l}-.0363 \\
\end{array}$ & .6950 & -.0290 & .6600 & -0.0290 & 7.7230 \\
\hline Uutilities & Baseline & Baseline & Baseline & \begin{tabular}{|l|l} 
Baseline \\
\end{tabular} & Baseline & $\begin{array}{l}\text { Baseline } \\
\end{array}$ & Baseline & Baseline \\
\hline Completed & $1.2730^{* * z}$ & .0010 & 1.2730 & .1600 & $1.0942^{2 *}$ & .0180 & 1.0442 & .1260 \\
\hline Terminated & Baseline & Baseline & Baseline & \begin{tabular}{|l|} 
Baseline \\
\end{tabular} & \begin{tabular}{|l} 
Baseline \\
\end{tabular} & Baseline & Baseline & Baseline \\
\hline World & $.9488^{* 1 *}$ & .0000 & $.9448^{* z *}$ & .0000 & $1.0411^{* * *}$ & .0000 & $1.0411^{* * *}$ & .0000 \\
\hline Emerging & .0109 & .9260 & .0109 & .7680 & Omitted & Omitted & Omitted & Omitted \\
\hline Frontier & Baseline & Baseline & \begin{tabular}{|l|l|} 
Baseline \\
\end{tabular} & Baseline & Baseline & Baseline & Baseline & Baseline \\
\hline
\end{tabular}

\section{Conclusion \& Discussion}

Given the significant and high quality prior probability that came to light in 1999 from KPMG, and its extensive dissemination, we expected to see a significant shift in behavior in the M\&A evaluation 
process, and therefore a reduction in overall M\&A activity. Introducing an $83 \%$ failure rate as a prior probability should substantially reduce future prospects for success and thus prevent a number of M\&As from going forward, especially those expected to generate only marginal gains. Yet two separate data sets and two different methods appear to show a complete lack of reaction to this ominous new data. It also helps explain high persistent failure rates over decades in the face of technology, data, process, and research evolution. One interesting finding, however, was that for KPMG clients, there was a mitigating effect. This would suggest that greater awareness of the risks and expert support to help people understand the importance of prior probabilities, could nudge decision makers in the right direction.

Although these results are not conclusive, they do provide substantial evidence that there is a level of insensitivity to prior probabilities in M\&A evaluation, and it is likely a reason failure rates remain extremely high [5][6][7]. This is important not only for M\&A decision makers, but also for those who seek to design decision support systems. Our analysis provides preliminary empirical evidence of the harmful use of heuristics in human judgement (i.e. ignoring prior probabilities) in the context of SDM and a follow-up study that examines this further is outlined in Section 6.

\section{Limitations}

There are a couple of limitations to this study that we are looking to address with additional work on this topic. First, cognitive biases occur at the individual level, and our data is at the organizational level. However, the heuristics used by individual managers ultimately impact their organizational strategies and outcomes. Thus, we ran a pilot study designed to examine how individuals make decisions in M\&A scenarios using traditional factors and prior probabilities. By varying the published failure rates in the survey study, we are able to explore human judgement under uncertainty and specifically examine the sensitivity (or insensitivity) to prior probabilities at the individual level. In this survey study we controlled for demographics and based on the literature on cognitive biases, we included independent variables on the following: Need for Cognition [42], Cognitive Reflection Test [43], and Impulsivity markers [43]. We plan to follow up with a larger scale study that examines human judgement in strategic decision making that will allow us to more clearly demonstrate the impact of this representativeness heuristic on M\&A failures.

The second limitation is that this is a review of only one cognitive bias, although one we believe the evidence shows that it is highly impactful. There are other cognitive biases that likely influence the process.
In decision making, parties required to make judgements tend to conflate what is accurate or fair with what provides the most benefit for that party. This is called self-serving bias [44]. For example, if you are on a management team and expect a promotion to come out of an M\&A that moves forward, that M\&A is likely to look more attractive to you than what the evidence dictates (John Kelly, Partner, Head of Global Integration and Separation Advisory for KPMG, personal interview, May 18, 2020). Another example of a bias that likely plays a role in M\&As is the hot-hand fallacy. If someone has had a few successes in a row, it is believed that their next endeavor will be a success. However, with this limited sample, it is more likely that a few successes in a row is due to random chance rather than being a predictor of future success, particularly if those successes came in other types of endeavors [45]. More cognitive biases need further investigation as they pertain to the M\&A process so a more comprehensive understanding can be developed.

\section{References}

[1] Chen, H., Chiang, R. H. L., \& Storey, V. C. (2012). Business Intelligence and Analytics: From Big Data to Big Impact. MIS Quarterly. 36(4), 1165-1188. Retrieved from https://ai.arizona.edu/sites/ai/files/MIS611D/chen-bidecember-2012.pdf

[2] Eisenhardt, K.M., \& Zbaracki, M.J. (1992). Strategic Decision Making. Strategic Management Journal, 13, 17-37. [3] Vance, A. (2011, September 8). Data Analytics: Crunching the Future. Bloomberg BusinessWeek. Retrieved from http://www.bloomberg.com/news/articles/2011-0908/data-analytics-crunching-the-future

[4] PwC. (2016). PwC's Global Data and Analytics Survey 2016. Retrieved from

http://www.pwc.com/us/en/advisory-services/datapossibilities/big-decision-survey.html

[5] KPMG. (1999). UNLOCKING SHAREHOLDER VALUE: THE KEYS TO SUCCESS. Retrieved from http://people.stern.nyu.edu/adamodar/pdfiles/eqnotes/KPMG M\&A.pdf

[6] Christensen, C.M., Alton, R., Rising, C., \& Waldeck, A. (2011). The Big Idea: The New M\&A Playbook. Harvard Business Review. Retrieved from https://hbr.org/2011/03/the-big-idea-the-new-ma-playbook [7] Lewis, A., \& McKone, D. (2016). So Many M\&A Deals Fail Because Companies Overlook This Simple Strategy. Harvard Business Review. Retrieved from https://hbr.org/2011/03/the-big-idea-the-new-ma-playbook [8] Bauer, F., \& Matzler, K. (2014). Antecedents of M\&A Success: The Role of Strategic Complementarity, Cultural Fit, and Degree and Speed of Integration. Strategic Management Journal, 35(2), 269-291.

[9] Bauer, F., \& Matzler, K., \& Wolf , S. (2016). M\&A and innovation: The role of integration and cultural differences: A central European targets perspective. International Business Review, 25, 76-86. 
[10] Marks , M.L., \& Marvis, P.H. (2011). Merge Ahead: A Research Agenda to Increase Merger and Acquisition Success. Journal of Business and Psychology, 26, 161-168. [11] Baker, E.W., \& Niederman , F. (2014). Integrating the IS functions after mergers and acquisitions: Analyzing business-IT alignment. Journal of Strategic Information Systems 23 (2014) 112-127.

[12] Haleblian J, Kim J.Y., Rajagopalan N. (2006). The influence of acquisition experience and performance on acquisition behavior: evidence from the U.S. commercial banking industry. Academy of Management Journal, 49(2), 357-370.

[13] Bruner, R.F. (2005). Deals from Hell: M\&A Lessons that Rise Above the Ashes. New York: John Wiley \& Sons, 2005. Retrieved from https://ssrn.com/abstract $=720984$ [14] Garzella, S., \& Fiorentino , R. (2014). A synergy measurement model to support the pre-deal decision making in mergers and acquisitions. Management Decision, 52(6). [15] Kahneman, D. (2011). Thinking Fast and Slow. New York: Farrar, Straus, and Giroux.

[16] Bingham, C.B. and Eisenhardt, K.M., 2011. Rational heuristics: the 'simple rules' that strategists learn from process experience. Strategic Management Journal, 32(13), pp.1437-1464.

[17] Kahneman, D., Slovic, P., \& Tversky, A. (1982). Judgment under uncertainty: heuristics and biases. Cambridge; New York : Cambridge University Press. [18] Al Khars, M., Pavur, R., \& Evangelopoulos, N. (2016). "Insensitivity To Prior Probability," Bias In Operations Management Context. In SWDSI Proceedings, 411-419. Oklahoma City, Oklahoma.

[19] Kahneman, D., \& Tversky, A. (1972). A Subjective Probability: A Judgement of Representativeness. Cognitive Psychology, 3, 430-454.

[20] Kahneman, D., \& Tversky, A. (1973). Psychology of prediction. Psychological Review, 80, 237-251.

doi: $10.1037 / \mathrm{h} 0034747$

[21] Bar-Hillel M. (1980). The base-rate fallacy in probability judgments. Acta Psychological, 44(3):211-233.

[22] Montibeller, G., \& von Winterfeldt, D. (2015).

Cognitive and Motivational Biases in Decision and Risk

Analysis. Risk Analysis, 35(7), 1230-1251.

[23] St. B.T. Evans, Jonathan. (1984). Heuristic and analytic processes in reasoning. British Journal of Psychology,

75(451-468).

[24] Pennycook, G., Trippas, D., Handley, S. J., \& Thompson, V. A. (2013). Base Rates: Both Neglected and Intuitive. Journal of Experimental Psychology: Learning, Memory, and Cognition. Advance online publication. doi: 10.1037/a0034887

[25] De Neys, W., \& Glumicic, T. (2008). Conflict monitoring in dual process theories of thinking. Cognition, 106, 1248 -1299. doi:10.1016/j.cognition.2007.06.002

[26] Hausman, C., \& Rapson, D. (2017). REGRESSION DISCONTINUITY IN TIME: CONSIDERATIONS FOR EMPIRICAL APPLICATIONS. NBER, Working Paper 23602. Retrieved from http://www.nber.org/papers/w23602

[27] SBN Staff. (2018). What's driving M\&A deals and how companies can capitalize on the activity. Smart Business. Retrieved from http://www.sbnonline.com/article/whats-driving-ma-dealsand-how-companies-can-capitalize-on-the-activity [28] IMAA. (2020). M\&A Statistics. Retrieved from https://imaa-institute.org/mergers-and-acquisitions-statistics/ [29] Statista. (2018). Global gross domestic product (GDP) at current prices from 2012 to 2022 (in billion U.S. dollars). Retrieved from

https://www.statista.com/statistics/268750/global-grossdomestic-product-gdp/

[30] Lall, S. (2008). IMF Survey: IMF Predicts Slower World Growth Amid Serious Market Crisis. IMF News. Retrieved from

http://www.imf.org/en/News/Articles/2015/09/28/04/53/sores $\underline{040908 \mathrm{a}}$

[31] Fan, G. (1996). Local Polynomial Modelling and Its Applications. London: Chapman and Hall.

[32] Auffhammer, M., \& Kellogg, R. (2011). Clearing the Air? The Effects of Gasoline Content Regulation on Air Quality. American Economic Review, 101(6), 2687-2722. [33] Anderson, M. L. (2014). Subways, Strikes, and Slowdowns: The Impacts of Public Transition Traffic Congestion. American Economic Review, 104(9), 2763-2796. [34] Bento, A., Kaffine, D., Roth, K., \& Zaragoza-Watkins, M. (2014). The Effects of Regulation in the Presence of Multiple Unpriced Externalities: Evidence from the Transportation Sector. American Economic Journal: Economic Policy, 6(3), 1-29.

[35] Resende, M. (2008). Mergers and acquisitions waves in the UK: a Markov-switching approach. Applied Financial Economics, 18, 1067-1074.

[36] Choi, S., \& Jeon, B. (2011). The impact of the macroeconomic environment on merger activity: evidence from US time-series data. Applied Financial Economics, 21, 233-249.

[37] Bailey, M. (2016). Real Stats: Using Econometrics for Political Science and Public Policy. New York: Oxford University Press.

[38] OECD. (2020). GDP by country and year 1994-2004. Retrieved from https://data.oecd.org/gdp/gross-domesticproduct-gdp.htm\#indicator-chart

[39] MSCI. (2020). MSCI COUNTRY CLASSIFICATION

STANDARD. Retrieved from https://www.msci.com/marketclassification

[40] Bloomberg Terminal. (2020). Mergers and Acquisitions 1994-2004.

[41] Giovanni, J. (2005). What drives capital flows? The case of cross-border M\&A activity and financial deepening.

Journal of International Economics, 65, 127-149.

[42] Cacioppo, J., \& Petty, R. (1984). The Efficient Assessment of Need for Cognition. Journal of Personality Assessment, 48(3), 306-307.

[43] Frederick, S. (2005). Cognitive Reflection and Decision Making. Journal of Economic Perspectives, 19(4), 25-42. [44] Babcock, L., \& Loewenstein, G. (1997). Explaining Bargaining Impasse: the Role of Self-Serving Biases. Journal of Economic Perspectives, 11(1): 109-26.

[45] Thaler, R, \& Sunstein, C. (2009). Nudge. New York: Penguin Books.

[46] Wharton. (2020). Audit Analytics - Audit Opinions. Wharton Research Data Services. Retrieved from https://wrds-www.wharton.upenn.edu/ 